\title{
The impact of paternal attachment training skills on the extent of maternal neonatal attachment in primiparous women: a clinical trial
}

\author{
SARA SETODEH ${ }^{1, \text { B, F }}$, FARKHONDEH SHARIF², A, G, MARZIEH AKBARZADEH ${ }^{3, \text { A, c-F }}$
}

\author{
${ }^{1}$ Department of Midwifery, School of Nursing and Midwifery, Shiraz University of Medical Sciences, Shiraz, Iran \\ ${ }^{2}$ Community Based Psychiatric Care Research Center, Department of Nursing, School of Nursing and Midwifery, \\ Shiraz University of Medical Sciences, Shiraz, Iran \\ ${ }^{3}$ Maternal-Fetal Medicine Research Center, Department of Midwifery, School of Nursing and Midwifery, Shiraz \\ University of Medical Sciences, Shiraz, Iran
}

A - Study Design, B - Data Collection, C - Statistical Analysis, D - Data Interpretation, E - Manuscript Preparation, F - Literature Search, G - Funds Collection

\begin{abstract}
Summary Background. Women in some social groups of the population may be less supported by their partners and may be more reliant on their employees.

Objectives. This study was designed to investigate the impact of paternal-attachment training skills on the extent of maternal neonatal attachment in primiparous women referred to the hospitals affiliated with the Shiraz University of Medical Sciences.

Material and methods. A randomized controlled trial was done in hospitals affiliated with the Shiraz University of Medical Sciences from October 2012 to September 2013. The present clinical trial was conducted on 150 husbands of qualified pregnant women. The intervention group took part in 90-minute sessions of maternal-fetal attachment training held once a week. On the other hand, the control group received routine pregnancy care. Both groups filled out Avant's checklist after the intervention to determine maternal-neonatal attachment. The data was then analyzed in SPSS using the independent $t$-test, chi-square test and Fisher's exact test. A rating of $p<0.05$ was considered as statistically significant.

Results. The median score in the total maternal-neonatal attachment group was [84; IQR,70-103], and in the control group it was [66; IQR, 49-86; $p<0.001]$. The Mann-Whitney $U$ test showed a significant difference between the median of the groups. In the five aspects of the checklist, Avant included dimensions such as mothers' emotional behavior, maternal-infant proximity behavior, maternal-infant caring behavior and maternal-infant attention. The relationship between the attachment and control groups was significant $(p<0.001)$. Conclusions. Paternal attachment behavior training skills increased the score of maternal-neonatal attachment. Thus, there is a need to educate fathers on prenatal care.
\end{abstract}

Key words: attachment, infant, maternal, paternal, training.

Setodeh S, Sharif F, Akbarzadeh $\mathrm{M}$. The impact of paternal attachment training skills on the extent of maternal neonatal attachment in primiparous women: a clinical trial. Fam Med Prim Care Rev 2018; 20(1): 47-54, doi: https://doi.org/10.5114/fmpcr.2018.73703.

\section{Background}

Prenatal maternal stress and anxiety can directly increase hypothalamic-pituitary-adrenal (HPA) axis secretion in the fetus [1]. It is well established that there is a good correlation between maternal and fetal plasma cortisol levels and that the cortisol levels have a direct effect on the development of the fetus [2]. There is also evidence that anxiety has negative effects on labor and is linked with pre-term delivery, which is associated with low birth weight and poor growth [3]. One way to cope with stress and labor pain is the use of non-pharmacological techniques. Mother and child attachment is the most unique and complex relationship that plays a role in the health care and nurturing of children at the beginning of life and their ability to establish effective communication in the future [4]. The development of this relationship has been confirmed in some studies, demonstrating a correlation between prenatal and postnatal attachment; postnatal depression may also be predicted by bonding failure [5-6]. Furthermore, optimal attachment in early infancy has been recognized as an integral component in the future development of a child [7]. Having a baby is a great evolutionary change for men who are experiencing fatherhood for the first time. However, the fathers' emotions have been taken into account less in comparison to the mothers' psychological changes [8]. In a study, it was shown that the transition to fatherhood among to-be-fathers may increase depressive and anxious feelings during pregnancy [9]. The fathers' attitude towards breast-feeding seemed to be ambiguous; some men feel that they have no involvement in the process of infant feeding, and they are excluded from this process. Midwives and child health nurses need to know about the experiences of fathers during pregnancy [10].

Thus, more attention should be paid to the fathers' readiness for accepting their roles. The role of fathers in improving the family's health should also be investigated. In cases where fathers are successful in sharing their wives' experiences of pregnancy and creating more interaction with their infants, they perform their paternal roles more desirably. According to some studies, fathers' cooperation in the pregnancy process is highly effective in their own, mothers', infants', and families' health [11].

The results of a study by Latifses et al. on expecting fathers indicated that those who had been trained to massage their pregnant partners, from the attachment level point of view, had a higher rate of marital adjustment, lower levels of anxiety and 
greater attachment in comparison with the control group of expecting fathers [12].

Moreover, the findings of a study were emphasized that paternal-fetal attachment before delivery was a prognostic factor for parental fetal attachment [13].

In general, if the attachment between the mother and fetus or newborn is not done, the possibility of unusual behavior in children rises. In the case of damage to relationship and attachment, problems such as temporary and transient relations, superficial affection, avoiding eye contact, destructive behavior towards self and others, cruelty towards animals, insufficient formal growth, inappropriate dietary patterns, and poor communication with peers will appear [14].

Of course, the results of the study by Ustunsoz et al. showed the parental-fetal attachment (PFA), indicating that pregnant women have more interest in the infant compared to their husbands [15].

In fact, paternal-fetal attachment is associated with paternal attachment during childhood, better outcomes of childhood adaptation and improvement of family dynamics [15]. Thus, the partners' involvement in the process of prenatal health care and training and the process of labor in order to improve fatherhood and for emotions and relationships involved in pregnancy and childbirth have been considered essential. For example, in a qualitative research, the sense of 'becoming a father, feeling like a father, its realization as a husband and creating new opportunities for involvement in child care' are expressed [16].

Fathers play an important role and responsibility in pregnancy. To accept different roles in pregnancy, it is necessary to have the necessary knowledge. Men's awareness can encourage them to participate in pregnancy, and as a result, the process of pregnancy and fatherhood will be enjoyable.

The influence of paternal attachment training skills behaviors on the extent of maternal neonatal attachment is a new area in medicine. Beside the childbearing period and the transfer of the parents is a critical period [17], and only a limited number of studies have been conducted in this area, the present study aims to explore the effect of teaching attachment be- haviors to paternal on their neonatal attachment in primiparous women was designed to be conducted.

\section{Objectives}

This study aimed at investigating the impact of attachment behavior training programs for expecting fathers and its influence on maternal-neonatal attachment.

Primary outcome: To investigate the effect of paternal-attachment training skills on the extent of maternal neonatal attachment.

Secondary outcome: To investigate the effect of paternalattachment training skills on maternal anxiety.

\section{Material and methods}

\section{Study design and population}

The research participants consisted of the primiparous women referring to the prenatal clinics of Hafez and Shoushtari hospitals, Shiraz, Iran, from October 2012 to September 2013. According to $\alpha=0.05$ and $1-b=0.80$ and considering the mean score of the maternal-fetal attachment of previous studies [15], $\mu_{1}=3.08, \mu_{2}=4.63$ and $\sigma=3$, mean difference $=1.55$, and using the following formula, a 120 -subject sample size was determined for the study.

$N=\frac{2\left(Z_{1-\partial / 2}+Z_{1-\beta}\right)^{2} \sigma^{2}}{\left(\mu_{2}-\mu_{1}\right)^{2}}$.

According to previous studies [15], considering $\alpha=0.05$ and $1-\beta=0.80$, mean difference $=1.55, \mu_{1}=3.08, \mu_{2}=4.63$ and $\sigma=3$, and using the following formula, a 120-subject sample size was determined for the study (Figure 1).

\section{Enrollment}

Not meeting inclusion criteria $(n=0)$ Declined to participate $(n=0)$

- Other reasons $(n=0)$

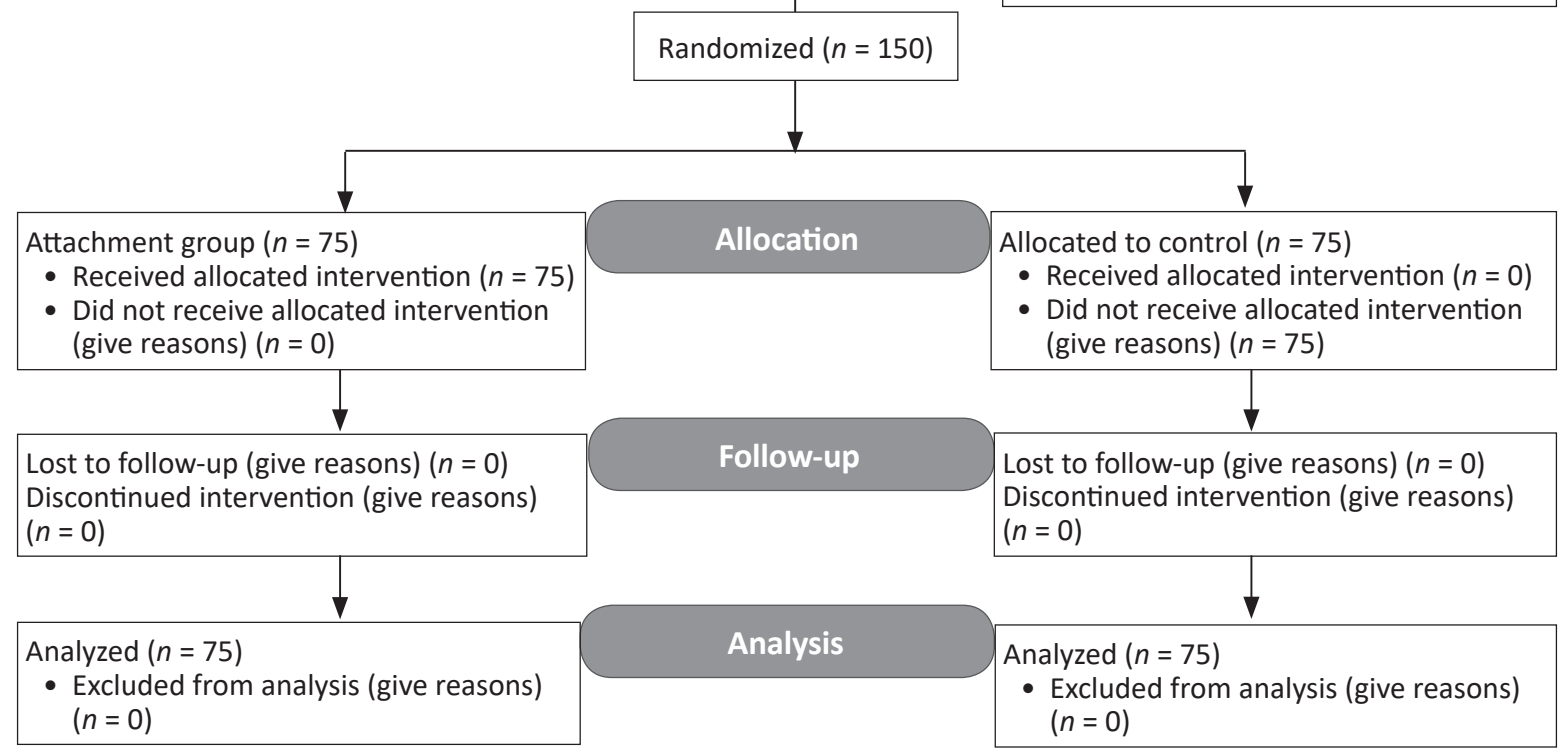

Figure 1. CONSORT 2010 flow diagram 
However, considering the probability of loss, 150 couples were selected through simple convenience sampling and randomly divided into an intervention and a control group by using a table of random numbers. In doing so, the first qualified individual was allocated to the intervention group, the second one to the control group, and the process was continued until 75 pregnant women were entered into each study group. After selecting the women, educational classes were held for their husbands.

\section{Inclusion and exclusion criteria}

The inclusion criteria of the study for the mothers were being at an age between 18 and 35 years; single and planned pregnancy; gestational age of 28-34 weeks; lack of psychological disorders, such as psychosis and schizophrenia; lack of chronic diseases, such as cardiovascular disorders, pulmonary disorders, hypertension and diabetes; experience of receiving pregnancy care in the previous months; the existence of low or average anxiety levels according to Spielberger's anxiety scale. In addition, the fathers' inclusion criteria were having at least a middle school degree, being under 45 years of age, being able to take part in the training classes and having signed the written informed consent. The exclusion criteria of the study were lack of cooperation by the father or mother during the training programs and the incidence of any problem during pregnancy, such as abruption, cord prolapsed, abnormal presentation and placenta previa. It should be mentioned that cesarean delivery was not considered as an exclusion criterion.

\section{Study group characteristics}

The median age of the women was [24; IQR, 26-32] years, and for the women in the control group, it was [25; IQR, 27-23; $p=0.081$ ] years. Other demographic characteristics are set out in Table 1. Along with this, the total value of all demographic characteristics is more than 0.05 , i.e. the two groups of inter- vention and control are homogeneous in terms of demographic characteristics.

\section{Intervention}

Before the intervention, the participants were enrolled in the research based on Spielberger's anxiety scale and the inclusion criteria. At first, the fathers were randomly divided into two groups by a table of random numbers (each group containing 75 couples). In the intervention group, the program was carried out, and the control group received only routine prenatal care. In both groups, educational materials and hospital routine prenatal care were taught to the pregnant women by their husbands. Thus, expectant mothers did not receive direct instruction from the researcher. The intervention group underwent attachment training during the $28^{\text {th }}$ to $34^{\text {th }}$ week of gestation, while the other group was considered as the control group. In doing so, the fathers were trained regarding attachment skills during four 60-90-minute sessions held once a week.

The pregnant mothers gave their written informed consents and filled out the demographic questionnaires and Avant checklist for all groups approx. 24 hours after delivery.

After delivery, maternal-neonatal attachment was evaluated by using the Avant checklist, which records the behavior of maternal attachment during breastfeeding; the attachment was evaluated 24 hours after birth. Considering the length of stay in the hospital, given that in vaginal childbirth the mothers are admitted to the hospital for one day and in cesarean section up to 2 days, maternal-infant attachment was examined as far as possible in the first 24 hours after birth for all mothers. Training courses were held as lectures, question and answer ( $Q$ \& A) sessions and discussions with the following titles, as shown in Table 2 .

After the interventions, the fathers were followed up via telephone contact and asked to transfer their information to their wives. A reminder session was also held at the $38^{\text {th }}$ week of gestation (to review the previous meetings, as well as ensure the accuracy of the content learned by fathers).

\begin{tabular}{|c|c|c|c|c|c|c|c|c|}
\hline \multicolumn{3}{|l|}{ Group } & \multirow{2}{*}{\begin{tabular}{|l|} 
Age \\
75 \\
\end{tabular}} & \multirow{2}{*}{\begin{tabular}{|l} 
Education \\
75 \\
\end{tabular}} & \multirow{2}{*}{$\begin{array}{l}\text { Job } \\
75 \\
\end{array}$} & \multirow{2}{*}{\begin{tabular}{|l} 
Partner age \\
75 \\
\end{tabular}} & \multirow{2}{*}{$\begin{array}{l}\text { Partner } \\
\text { education } \\
75 \\
\end{array}$} & \multirow{2}{*}{$\begin{array}{l}\text { Partner job } \\
75\end{array}$} \\
\hline Attachment & $n$ & valid & & & & & & \\
\hline & \multicolumn{2}{|l|}{ mean } & 24.14 & 2.48 & 1.04 & 28.56 & 2.16 & 1.2 \\
\hline & \multicolumn{2}{|l|}{ median } & 24 & $3 *$ & $1^{* *}$ & 29 & $2^{*}$ & $1^{* * *}$ \\
\hline & \multicolumn{2}{|l|}{ range } & 17 & 3 & 1 & 21 & 3 & 2 \\
\hline & \multicolumn{2}{|l|}{ minimum } & 18 & 1 & 1 & 21 & 1 & 1 \\
\hline & \multicolumn{2}{|l|}{ maximum } & 35 & 4 & 2 & 42 & 4 & 3 \\
\hline & \multicolumn{2}{|l|}{$I Q R=Q_{3}-Q_{1}$} & 4 & 2 & 0 & 5 & 2 & 0 \\
\hline \multirow[t]{11}{*}{ Control } & $n$ & & 75 & 75 & 75 & 75 & 75 & 75 \\
\hline & \multicolumn{2}{|l|}{ mean } & 25.04 & 2.6 & 1.0 & 29.50 & 2.4 & 1.2 \\
\hline & \multicolumn{2}{|l|}{ median } & 25 & 3 & 1 & 29 & 3 & 1 \\
\hline & \multicolumn{2}{|l|}{ range } & 17 & 3 & 1 & 18 & 3 & 2 \\
\hline & \multicolumn{2}{|l|}{ minimum } & 18 & 1 & 1 & 22 & 1 & 1 \\
\hline & \multicolumn{2}{|l|}{ maximum } & 35 & 4 & 2 & 40 & 4 & 3 \\
\hline & \multicolumn{2}{|l|}{$I Q R=Q_{3}-Q_{1}$} & 4 & 3 & 0 & 4 & 2 & 0 \\
\hline & \multirow{3}{*}{$\begin{array}{l}\text { Mann-Whitney U } \\
\text { Wilcoxon W } \\
\text { Z }\end{array}$} & & $2,350.500$ & $2,775.000$ & $2,551.500$ & $2,437.000$ & $2,682.500$ & $2,433.000$ \\
\hline & & & $5,200.500$ & $5,625.000$ & $5,401.500$ & $5,287.000$ & $5,532.500$ & $5,283.000$ \\
\hline & & & -1.745 & -0.386 & -1.048 & -1.418 & -0.767 & -1.523 \\
\hline & $p$ & & 0.081 & 0.700 & 0.295 & 0.156 & 0.443 & 0.128 \\
\hline
\end{tabular}

* mother's job: 1 - house work, 2 - employed; ** mother's education: 1 - primary school, 2 - secondary school, 3 - diploma, 4 - colleagues; $* * *$ partner's job: 1 - free job, 2 - governmental, 3 - unemployed. 


\begin{tabular}{|c|c|c|}
\hline Topic of session & Context & Method of education \\
\hline First session & $\begin{array}{l}\text { concepts of maternal-fetal and paternal-fetal attachment and their effects on the par- } \\
\text { ents' physical and mental health and fetal growth, parents' anxiety during pregnancy } \\
\text { and its reasons and impacts on the father's role in reduction of anxiety were discussed }\end{array}$ & $\begin{array}{l}\text { - lecture, } \\
\text { - group discussion, } \\
\text { - question and answer }\end{array}$ \\
\hline Second session & $\begin{array}{l}\text { parental attachment to the baby and attachment behaviors (by role playing) were } \\
\text { included }\end{array}$ & $\begin{array}{l}\text { - lecture, } \\
\text { - group discussion, } \\
\text { - question and answer, } \\
\text { - role playing }\end{array}$ \\
\hline Third session & $\begin{array}{l}\text { the way attachment is created, beginning of attachment and its signs, father's role } \\
\text { and acceptance of father's role were discussed }\end{array}$ & $\begin{array}{l}\text { - lecture, } \\
\text { - group discussion, } \\
\text { - question and answer, } \\
\text { - role playing }\end{array}$ \\
\hline Fourth session & $\begin{array}{l}\text { father's role in attachment, effect of focus on the fetus, consideration of the fetus as } \\
\text { an independent being, familiarity with the sensory abilities of the fetus and father's } \\
\text { role in breastfeeding after birth were included }\end{array}$ & $\begin{array}{l}\text { - lecture, } \\
\text { - group discussion, } \\
\text { - question and answer, } \\
\text { - role playing }\end{array}$ \\
\hline Reminder session & to review the previous meetings & $\begin{array}{l}\text { - lecture, } \\
\text { - group discussion, } \\
\text { - question and answer, } \\
\text { - role playing }\end{array}$ \\
\hline
\end{tabular}

\section{Measurment tools}

Maternal-neonatal attachment was rated using Avant's maternal attachment checklist. Avant's checklist is an instrument with 11 items under 3 behavior domains [18], i.e. passionate or loving behaviors (staring, fondling, kissing, talking); it includes 5 behaviors, each being evaluated 15 times.

The total score in this area is 75 . The second domain is keeping close behaviors (curling tightly the arm around baby and sticking him/her to herself, close body contact of mother and baby) and includes 3 behaviors, each being evaluated 15 times; the total score in this area is 45 . The third domain is caring behavior (patting the baby's back to cause him/her to belch, changing nappies and baby clothes). The mother and baby interacted for 15 minutes (e.g. being breastfed) with no awareness of the mother, and the behaviors were observed for 15 minutes for each mother. In the first 30 seconds of each minute, neonatal-maternal behaviors during breastfeeding were observed, and during the second half of observations, these behaviors were recorded. Each behavior observed in a minute was recorded only once. The total number of recorded behaviors in 15 minutes was considered. Thus, the maximum observed behavior in 15 minutes was 15 times. Since a total of 11 behaviors could be observed in 15 minutes, the maximum score for each unit of the study was 165 . In order to determine the validity, the content validity method, which was approved by experts (10 Iranian professors) in the study of Khurramrodi, was used. In order to determine the scientific reliability (reliability), the simultaneous observation test was used.

The validity and reliability of Savant's checklist by Khurramrodi were approved in Iran. Thus, two individuals simultaneously recorded the mothers' behaviors (in 10 women of the study population) in a checklist and then determined the correlation coefficient between them. Thus, the 0.98 correlation confirmed the reliability [19]. The reliability and validity indexes of the study by Khurramrodi were the basis for the current study.

Spielberger's anxiety scale was used in order to assess anxiety. This scale consists of 40 items, 20 of which assess the state of anxiety, and the other 20 investigate the trait anxiety. Accordingly, scores of 0-19, 20-40, 41-60 and 61-80 represent normal, mild, average and severe anxiety, respectively. The answers to multiple-choice questions (very low, low, high and very high) for each of the items were rated as $0.5,1,1.5$ and 2. The sum of the state and trait anxiety scores ranged from 20 to 80 [20]. Aghamohammadi used Spielberger's scale on 150 patients who had undergone surgery in 2007 and reported its reliability to be $97 \%$. The reliability and validity indexes of the study by Aghamohammadi were the bases of the current study [21].

\section{Ethical considerations}

This study was approved by the Ethics Committee of the Shiraz University of Medical Sciences (proposal No. 91-6123, IRCT:2012091910886N1). In addition, written informed consent was obtained from each participant before the study. The participants were also assured of the confidentiality of all their personal information. The researchers tried to observe all the participants' rights in accordance with Declaration of Helsinki.

\section{Statistical methods}

The collected data was encoded and analyzed in SPSS (version 11, SPSS Inc., Chicago, IL, USA). The results of the Shapiro-Wilk test showed that normality was not met for this data $(p<0.05)$, so we used the Mann-Whitney $\mathrm{U}$ test to compare attachment in the two groups. Therefore, in order to check the homogeneity of the demographic characteristics of the study population, the following tests were used: age by $t$-test, education by chi-square test, and Fisher's exact test for employment.

\section{Results}

The median score of the mothers' emotional behavior (first aspect of the Avant checklist) after the intervention was higher in the attachment group [43; interquartile range [IQR], 32-52] compared to the control group [32; IQR, 17-72; $p<0.001]$. Concerning maternal-infant proximity behavior (the second aspect of the Avant checklist), the median score in the attachment group was [19; IQR, 14-30], and in the control group, it was [17; IQR, 11-30; $p<0.001$ ] (Table 3). This showed a significant difference.

As to maternal-infant caring behavior (third aspect of the Avant checklist), the median score in the attachment group was [13; IQR, 0-20], and in the control group, it was [10; IQR, 5-19; $p<0.001$ ]. This revealed a significant difference (Table 3).

As to maternal-infant attention (the fourth dimension of the Avant checklist), the median score in the attachment group was [8; IQR, 5-19], and in the control group, it was [7; IQR, 3-12; $p<0.001]$. The result showed a significant difference. 


\begin{tabular}{|c|c|c|c|c|c|c|}
\hline \multicolumn{2}{|c|}{$\begin{array}{l}\text { Aspects of maternal-neonatal } \\
\text { attachment group }\end{array}$} & $\begin{array}{l}\text { total maternal-in- } \\
\text { fant attachment } \\
\text { behavior }\end{array}$ & $\begin{array}{l}\text { Aspect } 1 \\
\text { (mother's emo- } \\
\text { tional behavior) }\end{array}$ & $\begin{array}{l}\text { Aspect } 2 \\
\text { (maternal-infant } \\
\text { proximity) }\end{array}$ & $\begin{array}{l}\text { Aspect } 3 \\
\text { (maternal-infant } \\
\text { caring behavior }\end{array}$ & $\begin{array}{l}\text { Aspect } 4 \\
\text { (considering } \\
\text { maternal-infant } \\
\text { attention) }\end{array}$ \\
\hline \multirow[t]{7}{*}{ Attachment } & $n$ & 75 & 75 & 75 & 75 & 75 \\
\hline & mean & 84.14 & 42.58 & 19.46 & 13.42 & 8.78 \\
\hline & std. deviation & 7.64 & 5.05 & 3.15 & 3.40 & 2.16 \\
\hline & median & 84 & 43 & 19 & 13 & 8 \\
\hline & minimum & 70 & 32 & 14 & 0 & 5 \\
\hline & maximum & 103 & 52 & 30 & 20 & 19 \\
\hline & $I Q R=Q_{3}-Q_{1}$ & 33 & 20 & 16 & 20 & 14 \\
\hline \multirow[t]{7}{*}{ Control } & $n$ & 75 & 75 & 75 & 75 & 75 \\
\hline & mean & 65.94 & 30.80 & 17.20 & 10.49 & 7.38 \\
\hline & std. deviation & 8.60 & 6.39 & 3.77 & 3.44 & 2.02 \\
\hline & median & 66 & 32 & 17 & 10 & 7 \\
\hline & minimum & 49 & 17 & 11 & 5 & 3 \\
\hline & maximum & 86 & 42 & 30 & 19 & 12 \\
\hline & $I Q R=Q_{3}-Q_{1}$ & 37 & 25 & 19 & 14 & 9 \\
\hline \multirow[t]{7}{*}{ Total } & $n$ & 150 & 150 & 150 & 150 & 150 \\
\hline & mean & 75.05 & 36.69 & 18.33 & 11.96 & 8.08 \\
\hline & std. deviation & 12.21 & 8.24 & 3.65 & 3.71 & 2.20 \\
\hline & median & 77 & 38 & 18 & 12 & 8 \\
\hline & minimum & 49 & 17 & 11 & 0 & 3 \\
\hline & maximum & 103 & 52 & 30 & 20 & 19 \\
\hline & $I Q R=Q_{3}-Q_{1}$ & 54 & 35 & 19 & 20 & 16 \\
\hline Mann-Whitney U & 458.000 & $1,740.000$ & $1,461.000$ & $1,841.500$ & 347.500 & 458.000 \\
\hline Wilcoxon W & $3,308.000$ & $4,590.000$ & $4,311.000$ & $4,691.500$ & $3,197.500$ & $3,308.000$ \\
\hline Z & -8.864 & -4.069 & -5.100 & -3.690 & -9.271 & -8.864 \\
\hline$p$ & $\leq 0.001$ & $\leq 0.001$ & $\leq 0.001$ & $\leq 0.001$ & $\leq 0.001$ & $\leq 0.001$ \\
\hline
\end{tabular}

Regarding total maternal-infant attachment behavior, the median score of the attachment group was [84; IQR, 70-103], and that of the control group was [66; IQR, 49-86; $p<0.001$ ]. The result showed a significant difference (Table 3 ). The results in Table 3 show that the statistical value of total maternal neonatal attachment behavior and all aspects (mothers' emotional behavior, maternal-infant caring behavior, maternal-infant proximity, etc.) are less than 0.05 , which means the intervention group with classical training has a higher score than the control group with routine hospital care.

\section{Discussion}

The current study aimed to determine the effective role of educating fathers during pregnancy, from the psychological point of view, and also examine its impact on the level of parental attachment as an assumption. The study showed that the concepts of mother-infant attachment have been fully conveyed from men to the expectant mothers.

The results of our study showed that mother-infant attachment scores in all domains (mothers' emotional behavior, maternal-infant caring behavior, maternal-infant proximity, etc.) after the intervention in the attachment group were higher than in the control group and had a statistically significant relationship. Moreover, emotional behavior had the highest average, and the lowest average belonged to attentive behavior.
In the study of Fuller et al., it was indicated that the increase in the mother-infant attachment score of the experimental group in comparison with the control could be due to the fathers' trainings, conveying of concepts to the pregnant mothers, their readiness to take care of the newborns and facing mothers with the new roles. Touch and feto-talk trainings, along with fetus imagination, would lead to better mother-infant emotional behavior [22].

In the study by Siddikqui and Hagglof in 2000, a stronger maternal prenatal attachment was observed resulting from trainings. Better adjustment to the new role and readiness to breastfeed and attach better was also observed after the interventions [23]. The results of Siddikqui and Hagglof in 2000 on 100 pregnant women up to 3 months after birth showed that there was a direct relationship among maternal-fetal attachment, touch and self-concept with infant attachment in the postpartum period. There was a significant increase in the experimental group [23]. In another study, Bloom investigated the development and relation of attachment behaviors in pregnant adolescents. In that study, 79 singleton pregnant women in the age range of 12 to 19 years were divided into 3 age groups. The findings indicated that those mothers who paid more attention to the fetus during the third trimester after delivery showed more kind and caring behavior towards the newborn [24].

The results of the study showed that participation of parents in the educational program had a significant role in sup- 
porting physical and mental changes in pregnancy and increased maternal-fetal attachment. Therefore, the research shows that a direct relationship between the father's attention during pregnancy and the quality and strength of the relationship between father and child is also effective in the future [25].

Fathers' involvement in pregnancy, similar to mothers' involvement, is important; in addition to improving maternal-fetal attachment, it is also effective in other aspects of child growth factors, such as increasing birth weight, breast-feeding level, more efficient learning of language skills, further social development and a higher level of confidence [26].

The pregnancy period is a time when fathers experience several mental, psychological, social changes in order to obtain the necessary requirements to be a father [27]. Prenatal education to parents reduces the anxiety levels of parents, increases their comfort [28], helps them pay attention to each other and express love to their wife and enhances the feeling of attachment to the child [27].

The results of the recent studies are consistent with those of the current study in that paternal trainings increased maternal attachment. Although some studies have shown that fathers have positive expectations, a number of fathers in the first months of fatherhood had more feeling of discomfort rather than satisfaction [29]. The results of another survey showed that $11.7 \%$ of men showed signs of depression [30] and anxiety [31] during their wives' pregnancy, but at 6 weeks postpartum, their anxiety decreased.

In another study, the fathers experienced high levels of fatigue and irritability during the postpartum period, and prenatal and postpartum depression was observed in about $10 \%$ of men. Paternal depression also showed a moderate positive correlation with maternal depression [32].

Recent studies have focused more on mothers, but in the present study, the parents' anxiety was reduced by involving the fathers in the pregnancy and delivery process, as well as by increasing the knowledge and potential skills and the transmission power of the concepts to inter-couples. The differences in groups indicate that the impact of education on fathers, is a positive effect on involvement of fathers during pregnancy and childbirth.

A research study showed that important concerns that men may have included: 1 . Concerns about the health of the fetus; 2. Readiness for taking care of the baby after birth; 3. Experience of being pregnant; 4 . Experiences of fetal movements; and 5. The naming of the child. Mental concerns that parents may have lead to depression in mothers [14]. In fact, parent interaction during pregnancy leads to parents' mental concerns about pregnancy changes.

Providing an opportunity for parents to jointly talk about maternal and fetal attachment behavior can lead to an increase in maternal-fetal attachment. That is exactly the situation that we have provided in this study, which led to an increase in the maternal attachment to the fetus. It is believed that the increase of maternal-fetal attachment increases the signal sensitivity of the mother to the fetus. Attachments can facilitate the parent's communication; therefore, parents will secure a better connection [33].

In addition, the satisfaction of spouses received from each other leads to an increase in the harmony of the couple's life, thus reducing the level of maternal anxiety during pregnancy. As a result, maternal-fetal and neonatal attachment will increase [34].

Researchers are emphasize on understanding nature and the necessity of security relationship between parents and children. Other research in recent years has emphasized the importance of teaching parental affiliation and its impact on maternal-fetal attachment [35], reducing the mother's anxiety and increasing maternal-neonatal attachment $[36,37]$ infant mental health [38], and development of the baby [39].
Since most research has shown that the transition to fatherhood and pregnancy period is the most stressful time for men $[28,40,41]$, it is necessary to support them. Health care providers are recommended to hold training programs for self-efficacy of the fathers and stimulating their motivation to prepare themselves for this new period of their life. Mothers also benefit from the additional support.

\section{Strong points}

One of the strong points of this research was the fathers' participation in the process of pregnancy and childbirth; this creates a sense of responsibility for his wife's pregnancy. Along with this, the fathers' participation affected the communication between the parents and the newborn; this may improve the quality of the parents' role and help the parents to feel competent.

\section{Limitations of the study}

One of the limitations of the study was lack of proper conditions in the training classes for fathers to express their wives' problems in the presence of other men's wives. Therefore, coordination for the participation of all men was very difficult. For this reason, due to the absence of some of the participants, some of the early meetings were canceled and postponed to the next meeting. However, in subsequent meetings, regular topics were discussed, and thus, some of the men insisted on sharing their wives' pregnancy problems confidentially with the researcher and not discuss them in groups. This issue caused the investigators to answer the private questions of participant hours after the general meeting, and the time for the focus groups was reduced. This may have an impact on the results. Another limitation was the duration of training of the fathers and assessment of maternal-fetal attachment. In this study, we did not compare the results before and after the intervention.

It is recommended that future research should focus on attachment training for both husband and wife and should survey the effect of training on fetal and neonatal outcomes. A series of classes of prenatal care should be made compulsory for the father as well. In addition, the participation of fathers in pregnancy seems to reduce problems after childbirth. It is suggested that future studies should focus on the following topics: investigating the effect of attachment training to couples with severity of postpartum depression, self-efficacy of mothers in the intensity and duration of breastfeeding, physical growth and development of infants and the rate of infant morbidity and mortality. It is also recommended that the number of classes for fathers' education and the duration of maternal-fetal attachment assessment should increase.

\section{Conclusions}

The results revealed that the father's involvement in maternal-neonatal attachment Skills Training Classes and his involvement in the pregnancy and birth process would lead to his further interaction with the mother. On the other hand, the fathers' involvement would help the mothers to implement emotional, proximity and care skills of the neonate in the postnatal period.

Acknowledgements. The present article was extracted from Sara Setoudeh's M.Sc. thesis in midwifery (proposal No. 91-6123]. The authors would like to thank the Research Vice-chancellor of Shiraz University of Medical Sciences for financially supporting the study. They are also grateful to the manager of Hafez Hospital and all the study participants who cooperated in the research. The authors would like to thank the Center for Development of Clinical Research of Nemazee Hospital and Dr. Hossaini for data analysis and Dr. Nasrin Shokrpour for editorial assistance. 
Source of funding: The study was financially supported by the Research Vice-Chancellor of Shiraz University of Medical Sciences, Shiraz, Iran. Conflict of interest: The authors declare no conflict of interests.

\section{References}

1. Punamäki RL, Repokari L, Vilska S, et al. Maternal mental health and medical predictors of infant developmental and health problems from pregnancy toone year: does former infertility matter? Infant Behav Dev 2006; 29(2): 230-242.

2. de Weerth C, Buitelaar JK, Beijers R. Infant cortisol and behavioral habituation to weekly maternal separations: links with maternal prenatal cortisol and psychosocial stress. Psychoneuroendocrinology 2013; 38(12): 2863-2874.

3. Robertson E, Grace S, Wallington T, et al. Antenatal risk factors for postpartum depression: a synthesis of recent literature. Gen Hosp Psychiatry 2004; 26(4): 289-295.

4. Nemsadze K, Silagava M. Neuroendocrine foundation of maternal-child attachment. Georgian Med News 2010; 189(1): 21-26.

5. Kokubu M, Okano T, Sugiyama T. Postnatal depression, maternal bonding failure, and negative attitudes towards pregnancy: a longitudinal study of pregnant women in Japan. Arch Womens Ment Health 2012; 15(3): 211-216.

6. Damato EG. Prenatal attachment and other correlates of postnatal maternal attachment to twins. Adv Neonatal Care 2004; 4(5): 274-291.

7. Alhusen JL. A literature update on maternal-fetal attachment. J Obstet Gynecol Neonatal Nurs 2008; 37(3): 315-328.

8. Bartlett EE. The effects of fatherhood on the health of men: a review of the literature. The Journal of Men's Health \& Gender 2004; $1(2)$ : 159-169, doi: https://doi.org/10.1016/j.jmhg.2004.06.004.

9. Skjothaug T, Smith L, Wentzel-Larsen T, et al. Prospective fathers' adverse childhood experiences, pregnancy-related anxiety, and depression during pregnancy. Infant Ment Health J 2015; 36(1): 104-113.

10. Fägerskiöld A. A change in life as experienced by first-time fathers. Scand J Caring Sci 2008; 22(1): 64-71.

11. Jordan PL. Laboring for relevance: expectant and new fatherhood. Nurs Res 1990; 39(1): 11-16.

12. Latifses $V$, Estroff DB, Field T, et al. Fathers massaging and relaxing their pregnant wives lowered anxiety and facilitated marital adjustment. Journal of Bodywork and Movement Therapies 2005; (4)9: 277-282, doi: 10.1016/j.jbmt.2005.02.004.

13. Akbarzade M, Setodeh S, Sharif $F$, et al. The Effect of fathers' training regarding attachment skills on maternal-fetal attachments among primigravida women: a randomized controlled trial. IJCBNM 2014; 2(4): 259-267.

14. Seimyr L, Sjögren B, Welles-Nyström B, et al. Antenatal maternal depressive mood and parental-fetal attachment at the end of pregnancy. Arch Womens Ment Health 2009; 12(5): 269-279.

15. Ustunsoz A, Guvenc G, Akyuz A, et al. Comparison of maternal-and paternal-fetal attachment in Turkish. Midwifery 2010; 26(2): e1-e9, doi: 10.1016/j.midw.2009.12.006

16. Iwata H. Experiences of Japanese men during the transition to fatherhood. J Transcult Nurs 2014; 25(2): 159-166.

17. Lorensen M, Wilson ME, White MA. Norwegian families: transition to parenthood. Health Care Women Int 2004; 25(4): 334-348.

18. Toosi $\mathrm{M}$, Akbarzadeh $\mathrm{M}$, Sharif $\mathrm{F}$, et al. The reduction of anxiety and improved maternal attachment to fetuses and neonates by relaxation training in primigravida women. Women's Health Bulletin 2014; 1(1): e18968, doi: 10.17795/whb-18968.

19. Khoramrody R. [The effect of mothers touch on Maternal Foetal Attachment]. Thesis for M.S.c Degree of Iran University. 2000: 30-45 (original in Persian).

20. Adler J, Urech C, Finc N, et al. Response to induced relaxation during pregnancy: comparison of women with high versus low levels of anxiety. J Clin Psychol Med Settings 2011; 18(1): 13-21.

21. Aghamohammadi M. Religious preoperative anxiety. Ann Gen Psychiatry 2008; 69(4): 1195-1200.

22. Fuller S, Moore R, Lester W. Influence of family functioning on maternal-fetal attachment. J Perinatol 1993; 13(6): $453-460$.

23. Siddiqui A, Hagglof B. Does maternal prenatal attachment predict postnatal mother-infant interaction? Early Hum Dev 2000; 59(1): $13-25$.

24. Bloom KC. The development of attachment behaviors in pregnant adolescents. Nursing Res 2000; 25(2): 230-240.

25. Habib C, Lancaster S. The transition to fatherhood: identity and bonding in early pregnancy. J Theor Res and Practice about Men as Fathers 2006; 4(3): 235-253.

26. Garfield CF, Isacco A. Fathers and the well-child visit. Pediatrics 2006; 117(4): e637-645, doi: 10.1542/peds.2005-1612.

27. Golian Tehrani S, Bazzazian S, Dehghan Nayeri N. Pregnancy experiences of first-time fathers in Iran: a qualitative interview study. Iran Red Crescent Med J 2015; 17(2): e12271.

28. Condon JT, Boyce P, Corkindale CJ. The First-Time Fathers Study: a prospective study of the mental health and wellbeing of men during the transition to parenthood. Aust N Z J Psychiatry 2004; 38(1-2): 56-64.

29. Barclay L, Lupton D. The experience of new fatherhood: a socio-cultural analysis. J Adv Nurs 1999; 29(4): $1013-1020$.

30. Kamalifard M, Hasanpoor S, Babapour Kheiroddin J, et al. Relationship between fathers' depression and perceived social support and stress in postpartum period. J Caring Sci 2014; 3(1): 57-66.

31. Tohotoa J, Maycock B, Hauck YL, et al. Can father inclusive practice reduce paternal postnatal anxiety? A repeated measures cohort study using the Hospital Anxiety and Depression Scale. BMC Pregnancy Childbirth 2012; 31(12): 75.

32. Paulson JF, Bazemore SD. Prenatal and postpartum depression in fathers and its association with maternal depression: a meta-analysis. JAMA 2010; 303(19): 1961-1969.

33. Bryan AA. Enhancing parent-child interaction with a prenatal couple intervention. Am J Matern Child Nurs 2000; 25(3): 139-144.

34. Lang SN, Schoppe-Sullivan SJ, Kotila LE, et al. Daily parenting engagement among new mothers and fathers: the role of romantic attachment in dual-earner families. J Fam Psychol 2013; 27(6): 862-872.

35. Akbarzade $M$, Setodeh $S$, Sharif $F$, et al. The effect of fathers' training regarding attachment skills on maternal-fetal attachments among primigravida women: a randomized controlled trial. Int J Community Based Nurs Midwifery 2014; 2(4): 259-267.

36. Akbarzadeh $\mathrm{M}$, Rafiee $\mathrm{B}$, Asadi $\mathrm{N}$, et al. Comparative effect of attachment and relaxation training on perception of fetal movement and mother's anxiety in primiparous women: a randomized controlled study. Trends in Medical Research 2016; 11(2): 62-68.

37. Toosi M, Akbarzadeh M, Zare N, et al. Effect of attachment training on anxiety and attachment behaviors of first-time Mothers. Hayat 2011; 17(3): 69-79. Available from URL: http://hayat.tums.ac.ir/article-1-56-en.html.

38. Akbarzadeh M, Dokuhaki A, Joker A, et al. Teaching attachment behaviors to pregnant women: a randomized controlled trial of effects on infant mental health from birth to the age of three months. ASM 2015; 36(3): 175-183.

39. Dokuhaki A, Akbarzadeh M, Pishva N, et al. A study of the effect of training pregnant women about attachment skills on infants' motor development indices at birth to four months. Fam Med Prim Care Rev 2017; 19(2): 114-122, doi: https://doi.org/10.5114/ fmpcr.2017.67864.

40. Premberg A, Lundgren I. Fathers' experiences of childbirth education. J Perinat Educ 2006; 15(2): 21-28. 
41. Buist A, Morse CA, Durkin S. Men's adjustment to fatherhood: implications for obstetric health care. J Obstet Gynecol Neonatal Nurs 2003; 32(2): 172-180.

\section{Tables: 3}

Figures: 1

References: 41

Received: 03.05.2017

Reviewed: 10.05.2017

Accepted: 06.08.2017

Address for correspondence:

Marzieh Akbarzadeh, MSc

Maternal-Fetal Medicine Research Center

Department of Midwifery

School of Nursing and Midwifery

Shiraz University of Medical Sciences

Shiraz

Iran

Tel.: 0711-6474250

E-mail: akbarzadm@sums.ac.ir 